\title{
PROBLEMATIKA PEMAHAMAN TEKS NARASI PADA SISWA KELAS 4 SDN MARGOREJO 1/403 SURABAYA
}

\author{
Diki Ardiyanto $^{1)}$, Ida Sulistyawati' ${ }^{2)}$, Via Yustitia ${ }^{3)}$ \\ 1,2, 3 Universitas PGRI Adi Buana Surabaya \\ Corresponding author E-mail: dikiardiyanto21@gmail.com
}

\begin{abstract}
Abstrak
Kata Kunci :

problematika

pemahaman bacaan

Pemahaman teks narasi merupakan sebuah urgensi bagi siswa. Membaca bukan hanya tentang melihat simbol tetapi memahami makna dari simbol tersebut. Penelitian ini digunakan untuk mencari permasalahan atau permasalahan dalam memahami bacaan teks naratif. Tujuan penelitian ini adalah untuk mendeskripsikan masalah atau masalah yang dialami siswa dalam memahami teks bacaan narasi kelas 4 dalam pembelajaran online di SDN Margorejo 1/403. Penelitian ini menggunakan pendekatan deskriptif. Peneliti menggunakan 40 siswa kelas 4B dan mengambil 3 siswa sebagai subjek. Teknik yang digunakan peneliti menggunakan observasi dan tes. Metode observasi digunakan untuk mengukur pemahaman siswa melalui pembelajaran apa yang siswa pahami dari membaca dengan aspek bercerita. Sedangkan tes digunakan untuk 3 siswa yang paling sedikit dalam memaparkan pemahaman membaca. Hasil penelitian menunjukkan bahwa siswa mengalami masalah terkait pemahaman bacaan teks naratif dimana siswa kurang memahami pada indikator pemahaman bacaan: (1) siswa belum dapat menemukan ide pokok dari teks bacaan (2) siswa kurang memahami informasi dari bacaan (3) siswa belum mampu menentukan fakta dan pendapat (4) siswa belum mampu menyimpulkan bacaan. Saran bagi guru untuk menggunakan strategi membaca yang lebih baik dan guru untuk menganalisis bacaan. Agar siswa lebih teliti dalam membaca dan membuat korset untuk mengetahui isi bacaan yang dibacakan.
\end{abstract}

\section{Abstract:}

Keyword :

reading comprehension problems
Understanding narrative text is an urgency for students. Reading is not just about seeing symbols, but understanding the meaning of those symbols. This research is used to find problems or problems in understanding narrative text reading. The purpose of this study is to describe the problems or problems that can be understood by students in understanding narrative reading text in grade 4 in online learning at SDN Margorejo 1/403. This research uses a descriptive approach. Researchers used 40 grade $4 B$ students and took 3 students as subjects. The techniques used by researchers used observation and tests. The observation method is used to measure students' understanding through learning what students understand from reading with the aspect of storytelling. While the test used for the 3 students explained the least amount of reading comprehension. The results showed that students experienced problems related to reading comprehension of narrative text where students did not understand the reading comprehension indicators: (1) the students had not been able to find the main idea of the reading text (2) the students did not understand the information from the reading (3) the students had not been able to determine the facts and (opinion 4) students have not been able to conclude the reading. Suggestions for teachers to use better reading strategies and teachers to analyze reading. So that students are more careful in reading and make a corset to see the contents of the reading read. 


\section{Pendahuluan}

Pendidikan adalah masalah bersama, semua berkepentingan dengan pendidikan. Tetapi orang tua selalu menyerahkan anaknya ke lembaga pendidikan. Amat sangat jarang terdengar orang memuji. Rangsangan pendidikan yang diberikan secara jasmani dan rohani guna membantu tumbuh kembangnya untuk melanjutkan pendidikan kedepannya.

Pembelajaran yang dilakukan dapat diwujudkan dalam 6 aspek perkembangan anak adalah perkembangan nilai agama, fisik motorik, bahasa, sosio emosional, dan seni anak. Salah satu perkembangan anak adalah perkembangan bahasa. Belajar bahasa adalah berkomunikasi adapun 4 aspek dalam keterampilan berbahasa yaitu keterampilan menyimak, membaca, menulis, berbicara (Fanny, 2019). Peranan 4 aspek di atas sangat sangatlah penting. Tetapi pada dasarnya di kehidupan sehari hari keterampilan membaca sangat di perlukan dan sangat penting. Pemahaman bacaan sangat dibutuhkan di dalam dan luar dunia pendidikan (Aida, 2018) .

Pendidikan di sekolah dasar merupakan pendidikan formal paling dasar yang memberikan tujuan agar siswa dapat calistung (baca, tulis, dan berhitung) . siswa siap dan mampu menghadapi tingkat atau jenjang berikutnya. Berkaitan dengan pemberian bekal membaca dan menulis jadi pendidikan di sekolah dasar sangatlah penting khususnya dalam pemahaman membaca.

Menurut peraturan dari menteri pendidikan Nasional Nomor 22 tahun 2006 yang isinya mengenai standar isi dan standar kompetensi keberhasilan dalam mempelajari semua studi yang di pelajari. Membaca bukan hanya memandangi lambang-lambang yang tertulis. Jika siswa membaca dengan terpaksa maka informasi yang akan siswa terima tidak akan maksimal. Pembaca berupaya agar lambang-lambang yang di lihatnya menjadi bermakna dan paham apa yang di maksud lambang tersebut. Arti lainnya yaitu pengambilan dan pemahaman artian dan makna yang tersirat dalam bacaan yang ditulis disebut membaca ( $\mathrm{Su}, \mathrm{dkk}, 2019)$.

Menurut Tarigan (Dalam Irdawati, 2017:4) membaca merupakan sebuah proses yang dipakai orang yang membaca guna menerima suatu pesan, sebuah metode yang di pakai dalam proses komunikasi terhadap dirinya sendiri maupun dengan orang banyak meupakan pengkomunikasian jenisjenis lambang yang ditulis secara singkat pemetikan serta pemahaman maksud yang dikandungdalam sebuah tulisan disebut membaca. 
Pendapat Hogson (Kaban \& Lutmila, 2015:4) Membaca ialah sebuah alur yang dipakai dan di buat oleh orang yang membaca agar dapat menerima penyampaian pesannya melaui kata ataubahasa pada tulisan oleh penulis.

Berdasrkan definisi yang dijelskan maka bisa di tarik kesimpulan kalau membaca merupakan alur berubahnya bentuk, simbol, lambang, tanda tulisan, ke suatu bentuk penuh makna bagi orang yang membaca. Pembaca punya tujuan utamanya yaitu dapat menangkap informasi sesuai isi dan makna suatu yang dibaca.

Memahami suatu bacaan adalah kebutuhan yang harus di kuasai setiap orang. Seorang pembaca yang mampu dan lancar menguasai bacaan akan dapat mengimplementasikan pengalaman yang sebelumnya dengan pengetahuan baru yang didapatnya. Tetapi kemampuan ini tidak begitu saja didapatkan. Perlu latihan sejak dini. Disebabkan hal tersebut pembacaan sambil memahami harus dibiasakan sejak SD. Supaya siswanya tidak kesulitan dalam membaca

Dalam pembelajaran sekolah dasar banyak bacaan di buku seperti membaca teks narasi. Teks narasi adalah cerita sebuah kejadian maupun peistiwa sesuai dengan runtutan. Isi dari teks narasi fakta maupun berdasarkan pikiran si penulis Finoza dalam (Dalman, 2014:54)
Dalam penelitian ini peneliti menggunakan teks bacaan narasi dimana banyak teks narasi di dalam buku siswa. Serta bagaimana cara membaca siswa. Banyak siswa khususnya di sekolah dasar yang lancar membaca namun belum tahu apa makna dan isi yang mereka baca.

Dalam usaha memperoleh pemahaman teks bacaan narasi menggukan strategi. strategi yang di gunakan erat sekali terhadap keterlibatan pada memahami pendukung bacaan narasi siswa dengan factor pendukung. Supaya pemahaman siswa cukup untuk bacaan tersebut. Sebuah proses yang dimaksud dalam teks juga pengetahuan di miliki oleh orang yang membaca punya peran penting utama pada pembentukan artinya disebut membaca. Maka pentingnya bacaan teks narasi adalah teks narasi berfungsi untuk menceritakan kembali sebuah kejadian ataupun peristiwa yang sedang terjadi. Dalam menentukan strategi guru melihat faktot faktor yang berpengaruh menurut penjelasan diatas tadi peneliti akan mengkaji tentang "problematika pemahaman teks narasi untuk siswa kelas 4 SDN Margorejo 1/403 surabaya“

Penelitian ini bertujuan untuk mendapatkan masalah tentang memahami teks narasi untuk siswa kelas 4 SDN Margorejo 1/403 Surabaya. 


\section{Metode}

Metode Penelitian yang dipakai merupakan penelitian kualitatif deskriptif. Kualitatif merupakan data informasi secara deskriptif. Catatan yang dihasilkan peneliti dalam bentuk fakta maupun angka adalah data. Pada penelitian ini penggunaan data yang diakai adalah data deskriptif yang di peroleh dari observasi dan tes belajar siswa dengan 3 responden yang di pilih berdasarkan kesalahan terbanyak dalam penelitian Langkah-langkah penelitian, (1) Observasi siswa melalui pemahaman apa yang di dapat dengan bercerita tentang pemahaman yang di dapat (2) Hasil observasi akan di tarik 3 Subjek yang paling banyak kesalahan dan di lanjutkan dengan tes (3) Dari tes maka bisa di tarik keseimpulan problematika siswa. Data di peroleh dari sebuah metode dalam mengumpulkan data lalu di olah dan di analisis melalui suatu metode yang ditentukan. Untuk mengumpulkan data peneliti memakai teknik dibawah ini:

\section{Observasi terstruktur}

Observasi yang sudah di rencanakan dengan berstruktur mengenai yang akan di observasikan disebut observasi terstruktur. Kapan dan di mana, jadi observasi terstruktur dapat di lakukan jika apa bila peneliti menemukan variabel yang akan di amati. Dalam pengukuran subjek tersebut peneliti memakai instrument dalam penilaian setiap perilaku juga pengucapan. Instrumen di validasi oleh wali kelas 4B dengan indikator dari bercerita pemahaman menurut burhan. (Burhan, 2012:409) Observasi dilakukan untuk mencari siswa yang paling banyak kesalaham dalam menyampaikan pemahaman bacaan siswa melalui bercerita ulang. Dimana siswa membuat vidio lalu di kirim ke guru.

\section{Tes}

Untuk mendapatkan jawaban siswa baik berbentuk lisan atau tulisan atau dengan perbuatan sebagai alat untuk menilai pertanyaannya menggunakan tes. Jenis tes ini adalah bentuk cerita. Bentuk tes di pilih ini karena setiap langkah uraian penyelesaian dapat menunjukan problematika pemahaman bacaan. Tes di validasi oleh guru kelas 4B. Pada penelitian ini menggunakan tes tulis dengan cara siswa mengisi soal yang sudah di sajikan berhubungan dengan indikator pemahaman membaca dari sebuah teks narasi. Dengan indikator pemahaman membaca siswa adalah:

1. Mendapatkan ide pokok.

2. Mendapatkan informasi dari yang dibaca.

3. Mendapatkan fakta dan opini.

4. Dan dari bacaannya di buat sebuah kesimpulan. (Fauzidri, 2014:109)

Penganalisisan data yang telah dikumpulkan berdasarkan model pereduksian data, penyajian data 
sertavertivikasi atau menarik kesimpulan. Data yang direduksi adalah suatu penyerdahanaan dan pengabtraksian semua data yang di peroleh dari observasi dan tes. Penyajian data dilakukan dengan cara menyusun seluruh kegiatan belajar mengajar dan kesulitan siswa siswa serta apa penyebab kesulitan siswa, vertifikasi data adalah penarikan kesimpulan data yang telah di sajikan. penelitian ini peneliti menggunakan teknik triangulasi teknik. Dengan artian peneliti membandingkan informasi yang di peroleh dari narasumber itu juga dengan melalui perbedaan tekniknya. Teknik dengan trigulasi misalnya di peroleh dari observasi dan Tes

\section{Hasil dan Pembahasan}

Berdasarkan pembahasan Observasi yang di lakukan dari 40 siswa kelas 4B SDN Margorejo 1/403 Surabaya. 11 siswa masih bermasalah dalam menceritakan pemahaman teks bacaan yang sejalan dengan teori bercerita menurut (Burhan, 2012:409) menjelaskan bahwa indikator bercerita yaitu isi cerita yang tepat, detail cerita yang ditunjukkan tepat, keseluruhan cerita dengan makna yang tepat, logika cerita yang tepat, kata yang tepat, kalimat yang tepat, dan kelancarannya. Dari hasil observasi ada 3 siswa yang mendapat skor terendah dalam bercerita. Maka dari hasil tersebut dapat di tarik menjadi sampel untuk tes selanjutnya.

Dari $\mathrm{S}_{1}$ siswa masih belum menemukan informasi dari bacaan, menjelaskan gagasan utama, menentukan fakta opini, menarik simpulan. Dari $\mathrm{S}_{2}$ siswa siswa masih belum menemukan informasi bacaan, belum mampu menjelaskan makna dari bacaan. Dari $\mathrm{S}_{3}$ siswa masih belum menemukan informasi dari bacaan, belum mampu menjelaskan gagasan utama, belum mampu menarik simpulan

Berdasarkan uarian di atas dalam pemahaman bacaan di kelas 4 B SDN Margorejo 1 / 403. Masih terdapat problematika/masalah pemahaman bacaan yang merujuk pada teori(Fuzidri, Harris Effendi Thahar, 2014) sebagai berikut :

1. Siswa kurang mampu menjelaskan gagasan utama.

Dari 3 subjek yang di hasilkan dari observasi dan tes siswa kelas 4 B SDN Margorejo 1/ 403.2 dari 3 sampel siswa yang menjadi Subjek masih belum mampu menjelaskan gagasan utama yang terkandung dalam bacaan. Siswa hanya menjawab dengan judul bacaan yaitu rindu sekolah. Bukan gagasan utama yang terkandung dalam bacaan.

2. Menyebutkan informasi bacaan.

Dari 3 subjek yang di hasilkan dari observasi dan tes kelas 4 B SDN Margorejo 1/403. 3 siswa belum mampu 
menyebutkan informasi bacaan secara detail yang terkandung dalam bacaan. Berkaitan dengan sangat pentingnya pemahaman membaca teks narasi dengan baik tetapi, berdasarkan hasil penelitian ini. Siswa mengalami kesulitan memahmi informasi bacaan hal ini mengakibatkan pemahaman yang di capai siswa rendah.

3. Menentukan fakta dan opini.

Dari 3 subjek yang di hasilkan dari observasi dan tes kelas 4 B SDN Margorejo 1/ 403. 1 dari 3 siswa belum mampu menemukan fakta dan opini dari bacaan. Di karenakan siswa tidak bisa menerapkan sikap yang dapat di contoh dari bacaan. Karena siswa belum mencontohkan Sikap apa saja yang bisa jadi contoh dan penerapannya sehari hari dari bacaan secara faktual.

4. Menarik simpulan bacaan.

Dari 3 subjek yang di hasilkan dari observasi dan tes kelas 4 B SDN Margorejo 1/ 403. 1 dari 3 siswa belum mampu menarik simpulan dari bacaan yang di sajikan. Di karenakan subjek belum memahami isi atau inti bacaan sehingga Subjek tidak bisa berpendapat. . Melalui yang telah dijelaskan sebelumnya yaitu siswa kurang mampu terhadap pemahaman bacaan berdasarkan hasil peneltian. Setiap orang harus mengetahui apa saja permasalahanya agar dapat mencari solusi dari permasalahan tersebut. Hal tersebut di perkuat dengan teori probelmatika yang dapat di artikan sebagai masalah atau permasalahan menurut Ahmad Sabri (dalam Wiwik Angranti, 2018:06). Permasalahan dalam pehaman bacaan terdapat beberapa indikator yaitu (1) menjelaskan ide pokok (2) Menyebutkan informasi pada bacaan (3) Menemukan fakta dan opini (4) mengambil kesimpulan dari bacaan. Hal ini sejalan dengan penelitian dalam jurnal (Fuzidri, Harris Effendi Thahar, 2014) dalam keterampilan peningkatan membaca pemahaman yang menyatakan bahwa pada siklus pertama siswa pencapaiannya terhadap KKM (Kriteria Ketuntasan Minimal) belum bisa. Yang di perkuat dengan teori sumadyo, (dalam Frasandi \& Putri, 2019) pemahaman terhadap isi teks tau yang dibaca keseluruhannya merupakan membaca pemahaman. Pemahaman bacaan penting di kuasai oleh siswa untuk penunjang penyampaian informasi secara tepat (Yustitia \& Wardani, 2017). Peneliti menemukan bahwa siswa masih kurang dalam pemahaman membaca yang terdapat dalam semua indikator membaca pemahaman.

\section{Kesimpulan}

Hasil dari dari penelitian yang peneliti lakukan di kelas 4 B SDN Margorejo 1/403. 
Tentang problematika pemahaman bacaan teks narasi tahun 2020/2021 kesimpulan yang bisa diambil disini yaitu dari hasil penelitian menujukan bahwa siswa mengalami masalah yang terkait dengan pemahaman bacaan teks narasi dimana siswa kurang memahami dalam indikator membaca pemahaman : (1) siswa belum bisa menemukan gagasan utama dari teks bacaan (2) siswa belum paham informasi dari bacaan tersebut (3) siswa belum mampu menentukan fakta dan opini (4) siswa belum bisa menyimpulkan bacaan. Saran bagi guru untuk menggunakan strategi membacaan pemahaman yang lebih baik dan guru mengajak menganalisa suatu bacaan. Untuk siswa lebih teliti lagi dalam membaca dan berkonsetrasi agar mengetahui apa isi bacaan yang di baca.

\section{Daftar Pustaka}

Aida, S. (2018). Meningkatkan Keterampilan Membaca Awal Melalui Metode Struktural Analitik Sintetik Dengan Menggunakan Media Audio Visual. Jurnal Ilmiah Potensia, 3(2), 56-63.

Burhan, N. (2012). Penilaian Pembelajaran Berbahasa. BFFE-Yogyakarta.

Dalman. (2014). Keterampilan Membaca. RajaGrafindo.

Fanny, A. M. (2019, March). Analysis Of Pedagogical Skills And Readiness Of
Elementary School Teachers In Support Of The Implementation Of The 2013 Curriculum. In International Conference on Bussiness Law and Pedagogy (Vol. 1, No. 1, pp. 59-63).

Frasandy, R. N., \& Putri, S. (2019).

Peningkatan Kemampuan Menulis Ringkasan Isi Cerita melalui Model Pembelajaran CIRC di MIN 1 Pesisir Selatan. INVENTA: Jurnal Pendidikan Guru Sekolah Dasar, 3(1), 27-45.

Irdawati. (2017). Meningkatkan Kemampuan Membaca Permulaan Dengan Menggunakan Media Gambar Kelas 1 di Min Buol, ISSN 2354-614X. Jurnal Kreatif Tadulako Online, 5(4), 1-14.

Kaban, S., \& Lutmila, T. (2015). Peningkatan Kemampuan Membaca Pemahaman Melalui Pendekatan Saintifik Pada Siswa Kelas V SDN Pondok Labu 12 Pagi Jakarta Selatan. Jurnal Ilmiah PGSD, 7(2), 1-14.

Sun, K., Yu, D., Chen, J., Yu, D., Choi, Y., \& Cardie, C. (2019). Dream: A challenge data set and models for dialogue-based reading comprehension. Transactions of the Association for Computational Linguistics, 7, 217-231.

Yustitia, V., \& Wardani, I. S. (2017, August). Authentic assessment analysis based on the KKNI curriculum 
in applied statistics learning. In Ideas for 21st Century Education: Proceedings of the Asian Education
Symposium (AES 2016), November 22-

23, 2016, Bandung, Indonesia (p. 55).

Routledge. 